\title{
CD133 and Ki-67 expression is associated with gastrointestinal stromal tumor prognosis
}

\author{
CANRONG LU*, LICHENG LIU*, XIN WU and WENTONG XU \\ Department of General Surgery, Chinese People's Liberation Army General Hospital, Beijing 100853, P.R. China
}

Received February 18, 2013; Accepted August 2, 2013

DOI: $10.3892 / \mathrm{ol} .2013 .1564$

\begin{abstract}
CD133 ${ }^{+}$tumor cells have a greater potential ability for tumorigenesis, proliferation, invasion and metastasis compared with CD133- tumor cells. $\mathrm{Ki}-67$ is associated with cell proliferation in various tumors and has a markedly positive correlation with the prognosis of patients. However, there are a limited number of studies that have investigated the association between the prognosis of gastrointestinal stromal tumors (GISTs) and the two markers. The present study aimed to investigate CD133 and Ki-67 expression in GISTs and to explore their clinicopathological significance in the prognosis of patients with GISTs. A total of 111 GIST patients from the Chinese People's Liberation Army (PLA) General Hospital were retrospectively followed up and immunohistochemistry was used to detect CD133, Ki-67 and CD117 expression in the tumor samples. The survival rates of the patients were analyzed using the Kaplan-Meier method. The log-rank test, $\chi^{2}$ test and Cox's proportional hazards model were used to determine the association between CD133, Ki-67, CD117 expression and the prognosis of GIST. The 1-, 3- and 5-year survival rates were 93.0, 89.0 and $82.0 \%$, respectively, in all the patients. However, in the patients with $\mathrm{CD} 133^{+}$or $\mathrm{Ki}-67^{+}$, the 1-, 3- and 5-year survival rates were 81.0,61.5 and 50.0\% and $83.0,66.6$ and $53.0 \%$, respectively. Compared with the negative groups, the survival rates in the positive groups were statistically lower (CD133 log-rank, $\mathrm{P}=0.028$; Ki-67 log-rank, $\mathrm{P}=0.002$ ). The multivariate Cox analysis revealed that CD133 and $\mathrm{Ki}-67$ expression were considerable factors in the prognosis of GIST patients (CD117, $\mathrm{P}=0.495$; $\mathrm{CD} 133, \mathrm{P}=0.036$; $\mathrm{Ki}-67, \mathrm{P}=0.003)$. In conclusion, the positive expression of CD133 and Ki-67 was associated with a poor prognosis of GIST.
\end{abstract}

Correspondence to: Professor Wentong $\mathrm{Xu}$, Department of General Surgery, Chinese People's Liberation Army General Hospital, 28 Fuxing Road, Beijing 100853, P.R. China

E-mail: tibetoo@sohu.com

"Joint senior authorship

Key words: gastrointestinal stromal tumors, CD133, CD117, Ki-67, prognosis

\section{Introduction}

Gastrointestinal stromal tumors (GISTs) are mesenchymal tumors that arise from the gastrointestinal tract, showing differentiation toward the interstitial cells of Cajal and accounting for $<1 \%$ of all gastrointestinal neoplasms (1). GISTs predominantly and positively express DOG-1 (98\%) and CD117 (95\%) immunoglobulin (Ig). The estimated incidence of GISTs is $10-20$ million people annually worldwide. The majority of GISTs arise in the stomach (60\%), small bowel (30\%) and the esophagus and rectum (10\%) (2), and the remaining are extragastrointestinal, comprising a wide spectrum from a curable disorder to a highly malignant disease. With regard to the molecular markers, previous studies have revealed that p53, CD147, MCT1, DDX39 and NKp30 are associated with the prognosis of GISTs (3-7). However due to the weakness in their correlation, these markers, which are different from tumor size, mitotic rate or tumor site, are rarely mentioned in predicting the recurrence risk of GISTs and the prognosis of patients.

CD133 is a novel plasma membrane glycoprotein that was first identified in humans as a hematopoietic stem cell marker (8) and is currently used for the differentiation of stem cells from several tissues and cancer types (9). In nude mice, CD133+ tumor cells have been identified to have a greater potential ability for tumorigenesis compared with that of CD133- tumor cells $(10,11)$. Other studies have indicated that $\mathrm{CD} 133^{+}$tumor cells have a greater potential ability for proliferation, invasion and metastasis compared with that of CD133 cells (12-14). A study by Arne et al (15) revealed that CD133 was predominantly expressed in gastric GIST with KIT exon 11 mutations using the tissue microarray (TMA) method. This was defined as being a subgroup with a poor prognosis. There are no reports discussing the predictive value of the prognosis of GIST patients from a clinicopathological aspect.

$\mathrm{Ki}-67$, as a nuclear marker, is closely associated with tumor cell proliferation. Ki67 has been identified to have a positive correlation with the prognosis of various malignant tumors, including GIST. One study has indicated that Ki-67 is a strong prognosticator, though it is less valuable than the mitotic rate in GIST (16). The study by Nakamura et al (17) supports the hypothesis that $\mathrm{Ki}-67$ and the risk grade are useful for predicting the aggressive biological behavior of GIST.

The present study aimed to reveal the association between the molecular markers, $\mathrm{CD} 133$ and $\mathrm{Ki}-67$, and the prognosis 
of GISTs. As the diagnosis index, CD117 has been found to be located at the tumor cell membrane and cytoplasm (18) and the positive rate recorded as high as $95 \%$ in GISTs. The predictive value of CD117 in the prognosis of GISTs was also explored.

\section{Materials and methods}

Study population and follow-up. A total of 111 patients with GIST were admitted to the Chinese People's Liberation Army (PLA) General Hospital (Bejing, China) and underwent surgery between January 2004 and December 2010. The patients were retrospectively followed up. The clinical follow-up was completed in February 2011. The inclusion criteria consisted of an age of $\geq 18$ years old, GISTs diagnosed by histopathological and immunohistochemical methods and receipt of no other previous treatment. The exclusion criteria consisted of female patients who were pregnant or lactating, patients who had developed other malignancies during past five years and patients with other serious diseases.

Pathological examination of tumor samples. Paraffin wax sections (5- $\mu \mathrm{m}$ thick) of the GIST specimens were dewaxed in xylene and transferred to alcohol. The antibodies that were used were CD117 (rabbit anti-human polyclonal antibody; 1:100; Abcam, Cambridge, UK), Ki67 (rabbit polyclonal to proliferation marker; 1:1,000; Abcam) and CD133 (rabbit anti-human polyclonal antibody; 1:100; Biocare Medical, Concord, CA, USA). The endogenous peroxidase activity was blocked using $0.5 \%$ hydrogen peroxide in methanol and the sections were boiled in $10 \mathrm{mmol} / \mathrm{l}$ citrate buffer ( $\mathrm{pH} \mathrm{6.0)}$ in a microwave oven for $150 \mathrm{sec}$ for antigen retrieval. Non-specific binding was blocked by incubating the sections with $3 \%$ normal horse serum for $20 \mathrm{~min}$. The sections were incubated overnight at $4^{\circ} \mathrm{C}$ with a 1:1,000 dilution mouse monoclonal antibodies for CD133,CD117 and Ki-67, respectively. Poly-peroxidase-anti-mouse/rabbit $\mathrm{IgG}$ was applied to the sections for $30 \mathrm{~min}$ at $37^{\circ} \mathrm{C}$, then detected using 3,3'-diaminobenzine (DAB; Bioss, Beijing, China). The immunohistochemical reaction was developed with freshly prepared reagents of hematoxylin and mounted with glue $(19,20)$. The immunohistochemical reactions were then visualized under high power magnification (x400) using an Olympus BH2 microscope (field width, $0.5 \mathrm{~mm}$; Olympus Optical Co., Ltd., Tokyo, Japan) and scored into the following two categories based on the percentage of positively stained cells: CD117- and CD133-negative, $<10 \%$ and -positive, $>10 \%$; and Ki-67-negative, $<5 \%$ and -positive, $>5 \%$.

Study ethics. Approval for this study was obtained from the Chinese PLA General Hospital Ethics Committee. Informed consent was obtained from the patients for the use of the clinical material for research purposes.

Statistical analysis. SPSS 17.0 (SPSS Inc., Chicago, IL, USA) was used for the statistical analysis. The analysis was performed assuming a non-parametric distribution using the $\chi^{2}$ test. The actuarial survival rates were evaluated using Kaplan-Meier and log-rank tests. The multivariate survival analysis was performed using Cox's proportional hazards model. All the tests were two-tailed and $\mathrm{P}<0.05$ was considered to indicated a statistically significant difference.
Table I. Clinical characteristics of patients with GISTs.

\begin{tabular}{lc}
\hline Variable & Value \\
\hline Gender, $n$ & \\
Male:female & $59: 52$ \\
Age, years & $57(18-82)$ \\
Median (range) & \\
Presentation, $\mathrm{n}$ & 84 \\
Symptomatic & 27 \\
Incidental & \\
Follow-up time, months & $22(3-80)$ \\
Median (range) & \\
\hline
\end{tabular}

GISTs, gastrointestinal stromal tumors.

\section{Results}

Clinical characteristics. A total of 111 GIST patients (59 male and 52 female) with a median age of 57 years were included in this study. Of these, 27 were incidental cases. The median follow-up time was 22 months (range, 3-80 months) (Table I).

CD133, Ki-67 and CD117 expression in the tumor samples. The immunohistochemical results revealed that the positive expression rates for CD117, CD133 and $\mathrm{Ki}-67$ were $86.5 \%$ $(96 / 111), 43.2 \%(48 / 111)$ and $47.7 \%(53 / 111)$ in all the patients, respectively. The CD133 protein was expressed in the cell membrane or cell plasma, with a single focal expression (Fig. 1A). The Ki-67 protein was expressed in the nuclei of the GIST cells (Fig. 1B). The CD117 protein was expressed in the cell membrane or plasma (Fig. 1C). In the positive control group, there was no CD133 expression in the GIST cells (Fig. 1D), while CD133 was positively expressed in the gastric cancer and brain glioma cells (Fig. 1E and F). The histopathological type (spindle cell, epithelioid or mixed) was noted and the mitoses were counted using a $40 \mathrm{X}$ objective for 50 high-power fields (HPF), as recommended previously (21).

Association between CD133, KI-67 and CD177 expression and clinicopathological characteristics of GISTs. The survival analysis for all the GIST patients revealed that the 1-, 3- and 5-year survival rates were 93.0, 89.0 and $82.0 \%$, respectively. The recurrence rate was $10.6 \%$ with a recurrence time of 6-20 months. The highest survival rate was identified in the patients who underwent a complete tumor resection and were administered imatinib (400 mg/day) post-operatively. However, in the patients who did not undergo complete tumor resections and were not treated with imatinib post-operatively, the survival rate was the lowest. Considering the molecular markers, the survival rates in the $\mathrm{CD} 133^{+}$or $\mathrm{Ki}-67^{+}$groups were statistically lower than those in the negative groups (CD133, log-rank $\mathrm{P}=0.028$; and $\mathrm{Ki}-67, \log$-rank $\mathrm{P}=0.002)$. However, the rate was higher in the $\mathrm{CD} 117^{+}$group compared with that of the CD117 $7^{-}$group (log-rank $\mathrm{P}=0.001$ ) (Fig. 2). 

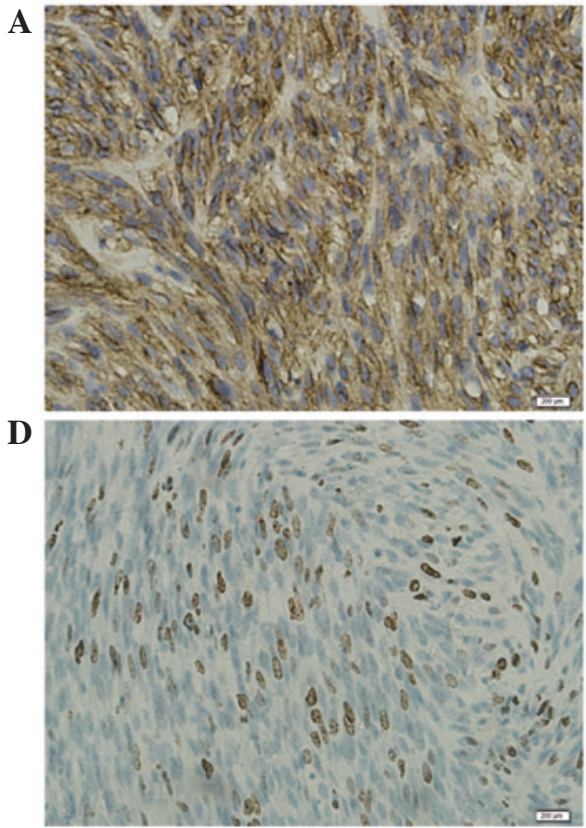

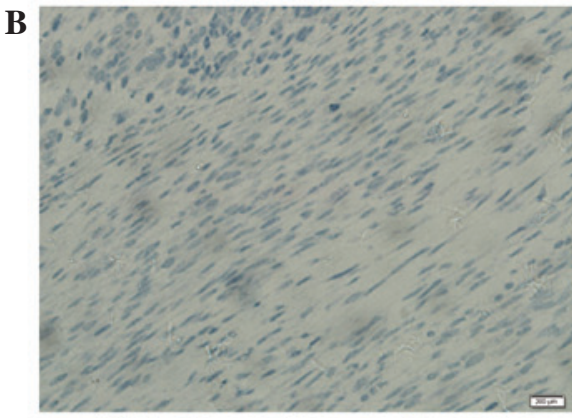

E

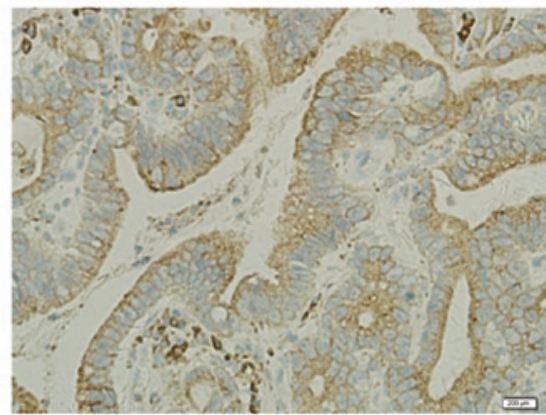

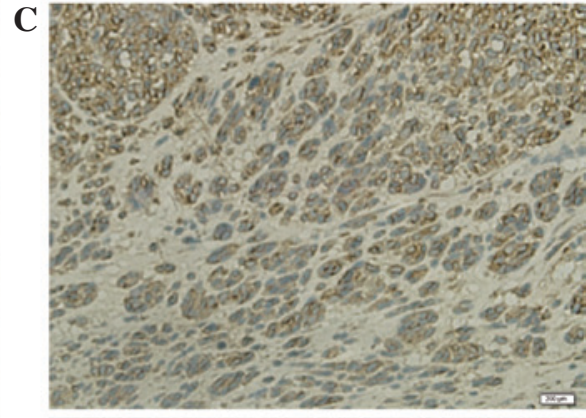

$\mathbf{F}$

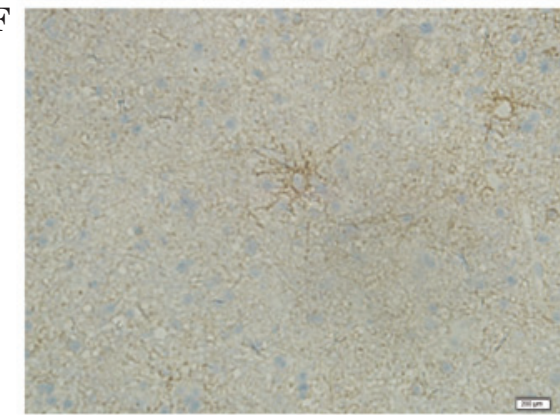

Figure 1. Immunohistochemistry of CD133, CD117 and Ki67 proteins in GIST and the controls. (A) CD133+ GIST. (B) CD133- GIST. (C) CD117 ${ }^{+}$GIST (D) Ki67+ GIST. (E) $\mathrm{CD}^{+} 33^{+}$gastric cancer. (F) CD133+ brain glioma cells. GIST, gastrointestinal stromal tumor. Bars, $200 \mu \mathrm{m}$.

A

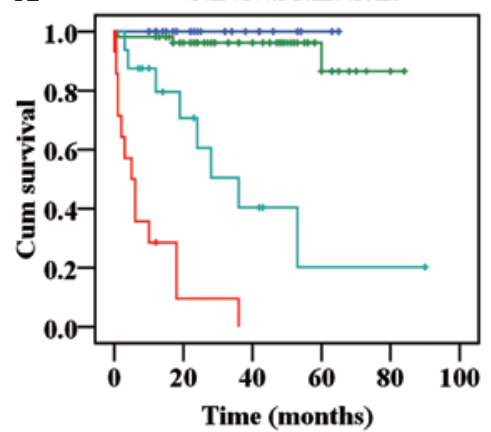

C

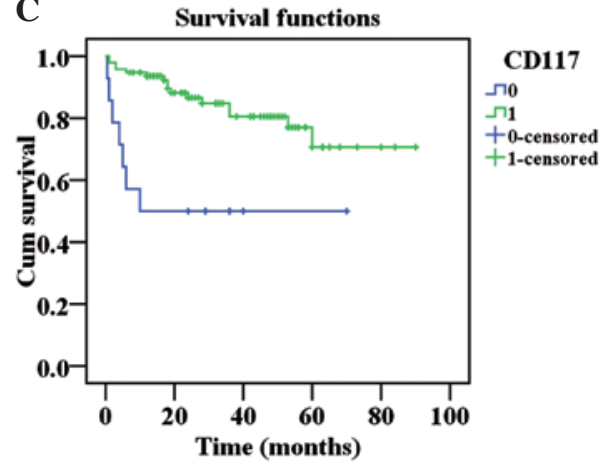

B

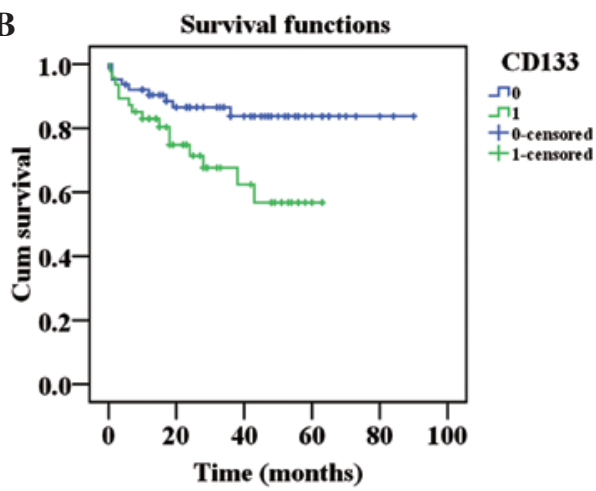

D

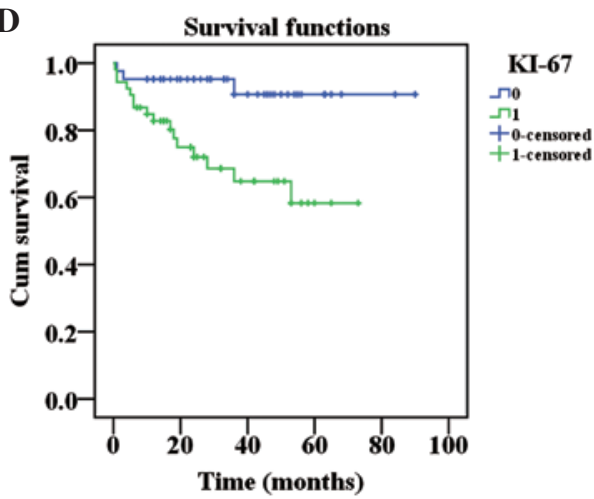

Figure 2. Analysis of the survival rates (Kaplan-Meier) and the comparison of the survival rates in the gastrointestinal stromal tumors (GISTs) groups (log-rank test). The highest survival rate was identified in patients that underwent a complete tumor resection and were administered imatinib (400 mg/day) post-operatively. The patients that did not undergo complete tumor resections and were not treated with imatinib post-operatively experienced the lowest survival rate (log-rank, $\mathrm{P}=0.000)$. (A) 1, Resected completely with imatinib; 2 , resected completely without imatinib; 3 , resected incompletely with imatinib; and 4, resected incompletely without imatinib. The survival rates in the (B) $\mathrm{CD} 133^{+}$or (D) Ki- $67^{+}$groups were statistically lower than those in the respective negative groups (CD133 log-rank, $\mathrm{P}=0.028$; Ki-67 log-rank, $\mathrm{P}=0.002)$. (C) The survival rate was higher in the $\mathrm{CD} 117^{+}$group rather than the negative group (log-rank $\mathrm{P}=0.001)$. (B-D) 1, positive; 0 , negative.

According to the risk grade of the USA National Institute of Health (NIH) (21), the GIST cases in the present study consisted of five extremely low-risk, 15 low-risk, 16 medium-risk and
75 high-risk cases. The comparison using the parameters of tumor diameter, tumor site, mitotic rate, NIH risk and depth of invasion revealed statistically significant differences 
Table II. Pathological parameters of GISTs in CD117, CD133 and Ki-67 proteins.

\begin{tabular}{|c|c|c|c|c|c|c|c|c|c|c|}
\hline \multirow[b]{2}{*}{ Variable } & \multirow{2}{*}{$\begin{array}{c}\text { Total, } \\
\mathrm{n}\end{array}$} & \multicolumn{2}{|c|}{ CD117, n } & \multirow[b]{2}{*}{ P-value } & \multicolumn{2}{|c|}{ CD133, n } & \multirow[b]{2}{*}{ P-value } & \multicolumn{2}{|c|}{ Ki-67, n } & \multirow[b]{2}{*}{ P-value } \\
\hline & & + & - & & + & - & & + & - & \\
\hline \multicolumn{11}{|l|}{ Diameter } \\
\hline$<5 \mathrm{~cm}$ & 26 & 23 & 3 & \multirow[t]{2}{*}{0.993} & 6 & 20 & \multirow[t]{2}{*}{$0.032^{\mathrm{b}}$} & 6 & 20 & \multirow[t]{2}{*}{$0.004^{\mathrm{a}}$} \\
\hline$\geq 5 \mathrm{~cm}$ & 85 & 73 & 12 & & 42 & 43 & & 47 & 38 & \\
\hline \multicolumn{11}{|l|}{ Site } \\
\hline Stomach & 45 & 40 & 5 & \multirow{3}{*}{0.250} & 18 & 27 & \multirow{3}{*}{0.829} & 14 & 31 & \multirow{3}{*}{$0.005^{\mathrm{a}}$} \\
\hline Small bowel & 34 & 31 & 3 & & 15 & 19 & & 17 & 17 & \\
\hline Others & 31 & 25 & 7 & & 15 & 17 & & 22 & 10 & \\
\hline \multicolumn{11}{|l|}{ Mitotic rate } \\
\hline$\geq 5 \mathrm{MF} / 50 \mathrm{HPFs}$ & 61 & 52 & 9 & \multirow[t]{2}{*}{0.886} & 30 & 31 & \multirow[t]{2}{*}{$0.000^{\mathrm{b}}$} & 38 & 23 & \multirow[t]{2}{*}{$0.001^{\mathrm{a}}$} \\
\hline$<5 \mathrm{MF} / 50 \mathrm{HPFs}$ & 50 & 44 & 6 & & 18 & 32 & & 15 & 35 & \\
\hline \multicolumn{11}{|l|}{ NIH risk } \\
\hline Extremely low & 5 & 4 & 1 & \multirow{4}{*}{0.978} & 1 & 4 & \multirow{4}{*}{$0.014^{\mathrm{b}}$} & 2 & 3 & \multirow{4}{*}{$0.008^{\mathrm{a}}$} \\
\hline Low & 15 & 13 & 2 & & 2 & 13 & & 4 & 11 & \\
\hline Middle & 16 & 14 & 2 & & 5 & 11 & & 3 & 13 & \\
\hline High & 75 & 65 & 10 & & 40 & 35 & & 44 & 31 & \\
\hline \multicolumn{11}{|l|}{ Depth of invasion } \\
\hline Mucosa & 15 & 14 & 1 & & 5 & 10 & & 6 & 9 & \\
\hline Muscular & 17 & 13 & 4 & \multirow{3}{*}{0.546} & 8 & 9 & \multirow{3}{*}{0.680} & 3 & 14 & \multirow{3}{*}{$0.010^{\mathrm{a}}$} \\
\hline Serous & 72 & 63 & 9 & & 33 & 39 & & 38 & 34 & \\
\hline Adjacent tissue & 7 & 6 & 1 & & 2 & 5 & & 6 & 1 & \\
\hline
\end{tabular}

${ }^{a}$ The differences were statistically significant between the $\mathrm{Ki}-67^{+}$and $\mathrm{Ki}-67^{-}$groups. There was no difference between the CD117 groups ${ }^{\mathrm{b}}$ Significant differences were observed between the $\mathrm{CD} 133^{+}$and $\mathrm{CD} 133^{-}$groups only when compared by the tumor diameter, mitotic rate and NIH risk. GISTs, gastrointestinal stromal tumors; MF, mitotic figures; HPFs, high power fields; NIH, National Institute of Health.

between the $\mathrm{Ki}-67^{+}$and $\mathrm{Ki} 67^{-}$groups, though no difference was identified for the CD117 marker. Significant differences were identified between the $\mathrm{CD}_{133^{+}}$and $\mathrm{CD} 133^{-}$groups only when they were compared using the tumor diameter, mitotic rate and $\mathrm{NIH}$ risk. In the $\mathrm{CD}_{133^{+}}$group, the cases with a high NIH risk accounted for $83.3 \%$ (40/48). Within the remaining pathological characteristics, the CD34-, smooth muscle actin (SMA)-, desmin- and vimentin-positive rates were 79.4, 46.8, 15 and $84.8 \%$, respectively (Table II).

The multivariate Cox model analysis suggested that CD133 and $\mathrm{Ki}-67$ expression, along with the tumor site, tumor diameter, mitotic rate, invading depth, completion of the resection, intraoperative rupture and adjuvant therapy were significant prognosis predictive factors $(\mathrm{P}<0.05)$. However, age, gender, margin distance, mucosal erosion, biopsy and CD34 and CD117 expression were not considered significant prognosis predictive factors $(\mathrm{P}>0.05)$ (Table III).

\section{Discussion}

The present study provided evidence that tumor size, mitotic index, tumor location and intraoperative tumor rupture are associated with the prognosis and recurrence of GISTs (22-24). Although p53, CD147, MCT1, DDX39 and NKp30 have been identified to be associated with the prognosis of GIST, the factors have never been considered prognostic predictors due to the weakness of their correlation.

CD133, also known as prominin-1 or $\mathrm{AC} 133$, is a novel plasma membrane glycoprotein that is composed of 865 amino acids with a molecular weight of $120 \mathrm{kDa}$. CD133 consists of an extracellular $\mathrm{NH}_{2}$-terminal, two extracellular ring structures, two small cysteine-rich intracellular cyclic structures and an intracellular $\mathrm{COOH}$-terminal. The gene is located on 4 p15.32 $(8,25)$. The CD133 protein localizes to membrane protrusions and is often expressed on adult stem cells, where it is believed to function in maintaining stem cell properties by suppressing differentiation. Studies have shown that CD133 is expressed in neurogenic tumors (26) and in the stem cells of lung, pancreatic, liver, prostate, gastric and colorectal cancer. In one previous study, CD133 ${ }^{+}$ tumor cells were identified to have a greater potential ability for tumorigenesis compared with that of the CD133- tumor cells $(10,11)$. Other studies have indicated that $\mathrm{CD}_{133^{+}}$tumor cells had a greater potential ability for proliferation, invasion and metastasis than CD133- cells (12-14). In addition, studies $(27,28)$ have indicated that CD133 is highly expressed in a variety of malignancies and was often observed to be associated with a poor prognosis. Furthermore, using the TMA method, Arne et al (15) revealed that CD133 was predominantly expressed in gastric GISTs with KIT exon 11 
Table III. Multivariate survival analysis using Cox's proportional hazards model in GISTs.

\begin{tabular}{|c|c|c|c|c|c|c|c|}
\hline \multirow[b]{2}{*}{ Variable } & \multirow[b]{2}{*}{$\mathrm{B}$} & \multirow[b]{2}{*}{ Wald } & \multirow[b]{2}{*}{ df } & \multirow[b]{2}{*}{ P-value } & \multirow[b]{2}{*}{ Hazard rate } & \multicolumn{2}{|c|}{$95 \% \mathrm{CI}$ for $\mathrm{HR}$} \\
\hline & & & & & & Lower & Upper \\
\hline Age (>60 vs. $\leq 60)$ & 0.023 & 1.696 & 1 & 0.193 & 1.024 & 0.988 & 1.060 \\
\hline Gender (male vs. female) & -0.234 & 0.346 & 1 & 0.556 & 0.791 & 0.363 & 1.726 \\
\hline Margin distance ( $>5 \mathrm{vs} . \leq 5 \mathrm{~cm})$ & 0.269 & 1.381 & 1 & 0.240 & 1.344 & 0.821 & 2.201 \\
\hline Mucosal erosion (yes vs. no) & 1.404 & 1.864 & 1 & 0.172 & 4.073 & 0.542 & 30.582 \\
\hline Biopsy (no vs. yes) & -0.303 & 0.502 & 1 & 0.429 & 0.739 & 0.319 & 1.708 \\
\hline CD34 (positive, $>10 \%$; negative, $<10 \%$ ) & -0.027 & 0.101 & 1 & 0.922 & 0.937 & 0.536 & 1.680 \\
\hline CD117 (positive, $>10 \%$; negative, $<10 \%$ ) & -0.214 & 0.466 & 1 & 0.495 & 0.808 & 0.437 & 1.491 \\
\hline Site $^{\mathrm{a}}$ & 0.622 & 25.015 & 1 & 0.000 & 1.863 & 1.460 & 2.378 \\
\hline Diameter ( $>5$ vs. $\leq 5 \mathrm{~cm})$ & 0.132 & 32.876 & 1 & 0.000 & 1.141 & 1.091 & 1.194 \\
\hline CD133 (positive, $>10 \%$; negative, $<10 \%$ ) & 0.221 & 2.094 & 1 & 0.036 & 1.250 & 1.014 & 1.534 \\
\hline Ki-67 (positive, >5\%; negative, $<5 \%$ ) & 1.887 & 8.868 & 1 & 0.003 & 6.602 & 1.906 & 22.863 \\
\hline Mitotic rate (>5/HPF vs. $\leq 5 / \mathrm{HPF})$ & 1.195 & 11.446 & 1 & 0.001 & 3.303 & 1.653 & 6.589 \\
\hline Depth of invasion ${ }^{\mathrm{b}}$ & 1.205 & 7.539 & 1 & 0.006 & 3.336 & 1.412 & 7.883 \\
\hline Complete resection (no vs. yes) & 2.807 & 24.674 & 1 & 0.000 & 16.555 & 5.470 & 50.104 \\
\hline Intraoperative rupture (no vs. yes) & -1.899 & 12.562 & 1 & 0.000 & 0.150 & 0.052 & 0.428 \\
\hline Adjuvant therapy (no vs. yes) & 1.757 & 35.579 & 1 & 0.000 & 5.796 & 3.254 & 10.325 \\
\hline
\end{tabular}

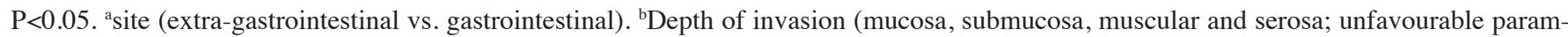
eter, serosa vs. favourable parameter, mucosa). GISTs, gastrointestinal stromal tumors; CI, confidence interval; HR, hazard ratio; HPF, high power field; B, regression coefficient; df, degree of freedom.

mutations, which was known as a subgroup with a poor prognosis. According to the previous findings, the positive expression of CD133 may be closely associated with survival. In the present study, the close follow-up of 111 GIST patients revealed that the 1-, 3- and 5-year survival rates of the CD133+ group were lower than those of the CD133- group. The present study further indicated that the expression of CD133 was a considerable factor in predicting the prognosis of GIST, as well as the tumor size, tumor location, mitotic index, depth of invasion and NIH risk classification. The findings coincided with the results of the study by Arne et al (15), in which a univariate survival analysis demonstrated a significant correlation between the presence of the CD133 protein and a shorter overall survival (hazard ratio, 2.23; $\mathrm{P}=0.027$ ). The multivariate analysis revealed that CD133 provided additional information on patient survival compared with age, gender, NIH risk classification and mutational status. Based upon the comprehensive recognition that $\mathrm{CD} 133^{+}$tumor cells have the characteristics of cancer stem cells, CD133 may play a significant role in the occurrence and development of GIST. Combining previous results and those of the present study, a new therapeutic approach targeting CD133 and a practical application using CD133 in predicting the prognosis for GIST may be a promising new approach, however, further studies are necessary.

The Ki-67 protein, also known as MKI67, exists in actively proliferating cells in the $\mathrm{G}_{1}, \mathrm{~S}$ and $\mathrm{G}_{2}$ phases, and is a proliferation-related nuclear marker of tumor cells (29). Certain studies have demonstrated that $\mathrm{Ki}-67^{+}$expression is closely associated with the aggressive biological behavior of tumor cells in GISTs (17). The marker represents a good prognostic predictor for GISTs (30). However, the significance of $\mathrm{Ki}-67$ in predicting the prognosis of GISTs remains in dispute.

Wong et al (16) identified that Ki-67 was less reliable than the mitotic count, although it proved to be useful in assessing the proliferation rate of the tumor cells in GISTs. The prognostic predictive value of Ki-67 in GISTs may have been evaluated more objectively in a large size sample case survival study with the various prognostic factors being taken into account. This was one of the aims of the present study. The study identified that the 1-, 3- and 5-year survival rates of the $\mathrm{Ki}-67^{+}$GIST group were lower than those of the Ki-67- group. The survival analysis further indicated that $\mathrm{Ki}-67$ expression was also a significant prognostic predictor for GISTs. The Wald index of $\mathrm{Ki}-67$ and the mitotic rate were similar (8.868 vs. 11.446), which indicated that Ki-67 was another useful molecular marker in predicting the prognosis of GISTs.

With regard to the molecular markers, CD117- expression was believed to be associated with an early post-operative recurrence in GISTs (31). This was confirmed in the present study. The expression of CD117 was not associated with the prognosis of GISTs. In summary, the present study indicated that the positive expression of CD133 and Ki-67 were indicators of poor prognosis in GISTs. However, the smaller sample volume was a limitation in the present study. The study may promote the clinical application of the two markers and provide insight into novel therapeutic targets in the treatment of GISTs in the future. 


\section{References}

1. Gupta P, Tewari M and Shukla HS: Gastrointestinal stromal tumors. Surg Oncol 17: 129-138, 2008.

2. Katz SC and DeMatteo RP: Gastrointestinal stromal tumors and leiomyosarcomas. J Surg Oncol 97: 350-359, 2008.

3. Delahaye NF, Rusakiewicz S, Martins I, et al: Alternatively spliced NKp30 isoforms affect the prognosis of gastrointestinal stromal tumors. Nat Med 17: 700-707, 2011.

4. Kikuta K, Kubota D, Saito T, et al: Clinical proteomics identified ATP-dependent RNA helicase DDX39 as a novel biomarker to predict poor prognosis of patients with gastrointestinal stromal tumor. J Proteomics 75: 1089-1098, 2012.

5. González-Cámpora R, Delgado MD, Amate AH, et al: Old and new immunohistochemical markers for the diagnosis of gastrointestinal stromal tumors. Anal Quant Cytol Histol 33: 1-11, 2011.

6. Zong L, Chen P and Xu Y: Correlation between P53 expression and malignant risk of gastrointestinal stromal tumors: evidence from 9 studies. Eur J Surg Oncol 38: 189-195, 2012.

7. de Oliveira AT, Pinheiro C,Longatto-Filho A, et al: Co-expression of monocarboxylate transporter 1 (MCT1) and its chaperone (CD147) is associated with low survival in patients with gastrointestinal stromal tumors (GISTs). J Bioenerg Biomembr 44: 171-178, 2012.

8. Yin AH, Miraglia S, Zanjani ED, et al: AC133, a novel marker for human hematopoietic stem and progenitor cells. Blood 90: 5002-5012, 1997.

9. Shmelkov SV, St Clair R and Lyden D and Rafii S: AC133/CD133/Prominin-1. Int J Biochem Cell Biol 37: 715-719, 2005.

10. Chen YC, Hsu HS, Chen YW, et al: Oct-4 expression maintained cancer stem-like properties in lung cancer-derived CD133-positive cells. PLoS ONE 3: e2637, 2008.

11. Matsumoto K, Arao T, Tanaka K, et al: mTOR signal and hypoxiainducible factor-1 alpha regulate CD133 expression in cancer cells. Cancer Res 69: 7160-7164, 2009.

12. Qin K, Jiang X, Zou Y, et al: Study on the proliferation and drug resistance of human brain tumor stem like cells. Cell Mol Neurobiol 30: 955-960, 2010

13. Moriyama T, Ohuchida K, Mizumoto K, et al: Enhanced cell migration and invasion of CD133+ pancreatic cancer cells cocultured with pancreatic stromal cells. Cancer 116: 3357-3368, 2010.

14. Ding W, You H, Dang H, et al: Epithelial-to-mesenchymal transition of murine liver tumor cells promotes invasion. Hepatology 52: 945-953, 2010.

15. Arne G, Kristiansson E, Nerman O, et al: Expression profiling of GIST: CD133 is associated with KIT exon 11 mutations, gastric location and poor prognosis. Int J Cancer 129: 1149-1161, 2011.

16. Wong NA, Young R, Malcomson RD, et al: Prognostic indicators for gastrointestinal stromal tumours: a clinicopathological and immunohistochemical study of 108 resected cases of the stomach. Histopathology 43: 118-126, 2003.
17. Nakamura N, Yamamoto H, Yao T, et al: Prognostic significance of expressions of cell-cycle regulatory proteins in gastrointestinal stromal tumor and the relevance of the risk grade. Hum Pathol 36: 828-837, 2005

18. Miettinen M and Lasota J: KIT (CD117): a review on expression in normal and neoplastic tissues, and mutations and their clinicopathologic correlation. Appl Immunohistochem Mol Morphol 13: 205-220, 2005.

19. Elias J (ed): Immunhistopathology: A Practical Approach to Diagnosis. ASCP Press, Chicago, IL, 1990

20. Taylor CR: Immunoperoxidase techniques: practical and theoretical aspects. Arch Pathol Lab Med 102: 113-121, 1978.

21. Joensuu H: Risk stratification of patients diagnosed with gastrointestinal stromal tumor. Hum Pathol 39: 1411-1419, 2008.

22. Dematteo RP: Personalized therapy: prognostic factors in gastrointestinal stromal tumor (GIST). J Gastrointest Surg 16: 1645-1647, 2012.

23. McCarter MD, Antonescu CR, Ballman KV, et al; American College of Surgeons Oncology Group (ACOSOG) Intergroup Adjuvant Gist Study Team: Microscopically positive margins for primary gastrointestinal stromal tumors: analysis of risk factors and tumor recurrence. J Am Coll Surg 215: 53-59, 2012.

24. Attili SV, Ananda B, Mandapal T, et al: Factors influencing progression-free survival in gastrointestinal stromal tumors with special reference to pathologic features, cytogenetics, and radiologic response. Gastrointest Cancer Res 4: 173-177, 2011.

25. Weigmann A, Corbeil D, Hellwig A and Huttner WB: Prominin, a novel microvilli-specific polytopic membrane protein of the apical surface of epithelial cells, is targeted to plasmalemmal protrusions of nonepithelial cells. Proc Natl Acad Sci USA 94: 12425-12430, 1997.

26. Singh SK, Hawkins C, Clarke ID, et al: Identification of human brain tumour initiating cells. Nature 432: 396-401, 2004.

27. Chew MF, Teoh KH and Cheah PL: CD133 marks for colorectal adenocarcinoma. Malays J Pathol 34: 25-28, 2012.

28. Reggiani Bonetti L, Migaldi M, Caredda E, et al: Increased expression of CD133 is a strong predictor of poor outcome in stage I colorectal cancer patients. Scand J Gastroenterol 47: 1211-1217, 2012.

29. Hutchins JR, Toyoda Y, Hegemann B, et al: Systematic analysis of human protein complexes identifies chromosome segregation proteins. Science 328: 593-599, 2010.

30. Artigiani Neto R, Logullo AF, Stávale JN and Lourenço LG: $\mathrm{Ki}-67$ expression score correlates to survival rate in gastrointestinal stromal tumors (GIST). Acta Cir Bras 27: 315-321, 2012.

31. Lamba G, Ambrale S, Lee B, et al: Recent advances and novel agents for gastrointestinal stromal tumor (GIST). J Hematol Oncol 5: 21, 2012. 